\title{
Study on the New Generation of Migrant Workers Citizenization
}

\author{
-- Based on SWOT analysis
}

\author{
Qiao Juling \\ School of Management \\ University of Jinan \\ Jinan, China \\ E-mail: qiao58@126.com
}

\author{
Chen Lishuang \\ School of Management \\ University of Jinan \\ Jinan, China \\ E-mail: lishuangchen88@163.com
}

\begin{abstract}
At present, migrant workers urbanization has entered a new period of development. The new generation of migrant workers is the main object of migrant workers urbanization. Analysis of the advantages and disadvantages of the risk factors of urbanization of new generation migrant workers scientifically and objectively is helpful to grasp the essence of the whole migrant workers urbanization, and is helpful to solve the problems of the migrant workers urbanization. Therefore, in the SWOT analysis method, make a comprehensive analysis of strengths and weaknesses, the opportunities and challenges of the new generation of migrant workers urbanization to conclude that there are a lot of advantages including higher cultural level, the desire to integrate into the city, life of closing to the citizens, a wider range of employment for the new generation of migrant workers, but there are also disadvantages and threats. In the process of migrant workers urbanization at present, we should seize the opportunity, make use of the advantage and overcome the disadvantage and threats, hoping to provide some help to find the ways of migrant workers urbanization.
\end{abstract}

Keywords: the new generation; migrant workers; citizenization; SWOT; analysis

\section{INTRODUCTION}

In 2010, the central no.1 document issued by the State Council first proposed the "new generation of migrant workers". The new generation of migrant workers is born since 1980, working in the city of rural household population. They accounted for $60 \%$ of the migrant workers, and have become the subject of rural migrant workers. Compared with the older generation of migrant workers, the new generation of migrant workers has no feelings to the land and love City genuinely. Group characteristics of the new generation of migrant workers are summarized by some experts: "three high and one low". It is mainly reflected as follows: the relatively high level of education, the high expected value of the occupation, the material and the high material and spiritual enjoyment requirement, and the low work tolerance. The new generation of migrant workers urbanization is the final process of rural labor transfer in China. It is also an inevitable trend of urbanization. In the scientific method of SWOT analysis, analysis of the strengths and weaknesses and the opportunities and threats can provide some help to find the scientific and reasonable path of migrant workers urbanization.

\section{THE STRENGTHS OF THE NEW GENERATION MIGRANT WORKERS CITIZENIZATION}

A. The new generation of migrant workers has higher culture degree and strong consciousness of accepting the education

First of all, cultural degree of new generation migrant workers into the city is relatively high, so that they have a greater advantage. It is specifically manifested: first, cultural degree of improvement can make the employment of migrant workers in a higher technological content, income is also higher work. Second, cultural degree of improvement can make the employment of migrant workers awareness strengthening, more to adapt to the city life.

Secondly, the new generation of migrant workers has strong consciousness of accepting the education. The new generation of migrant workers expects to change their and their children's fate through education. First, the new generation of migrant workers has a strong desire to learn. In order to meet the highly developed society, most of them in hope that by raising the level of knowledge and skills of its own, expanding employment, so that they can live in the town of long-term stability. Second, the new generation of migrant workers pays much attention to their children's learning. In order to let their children receive better education early, they let their children come into the city with themselves, and receive the same education with the urban children. They hope their children to have a better space for development in the future.

\section{B. The new generation of migrant workers desire to integrate into the city to become real people}

The new generation of migrant workers has no longer take working in the city as a means of livelihood, but hope to integrate into the city, and in the end become the city people. First of all, most of the new generation of migrant workers has no farming experience and the agricultural production skills. They don't want to return to the rural areas and have no ability to live. Secondly, the new generation of migrant workers likes glamorous lifestyle and entertainment. The new generation of migrant workers 
is grown in the diversified world. Their thinking is active, and they have great experience. They are easy to accept new things, and they aspire after material and spiritual life of city.

\section{The life of the new generation of migrant workers is gradually close to the citizens}

The new generation of migrant workers is not only the builders and the producers of the modern city, but also the city of the consumer. The new generation of migrant workers no longer saves money on food and expenses like the older generation of migrant workers, but more attention to their quality of life. They develop gradually toward similar patterns of consumption with the citizens. Their life is gradually close to the citizens. They begin to focus on instrumentation, neat and clean appearance. Their appearance is no longer unkempt. Many migrant workers feel that their good image is good for the usual communication and employment. The use of the mobile phone of the new generation of migrant workers has been very popular. They not only access to information resources through books, newspapers, radio, television, but also the Internet began to appear in the life. Nearly half of the new generation of migrant workers has computer online experience, a part of migrant workers Internet via mobile phone.

\section{The scope of employment of new generation of migrant workers is more widely, they have higher expectations for the future occupation}

First, the scope of employment of new generation of migrant workers is more widely. In recent years, China's rapid development of the third industry has provided new jobs for the new generation of migrant workers, expanding employment channels. Of the new generation of migrant workers, manufacturing employees account for the largest proportion, and practitioners in the proportion of the third industry are increased, the ratio of engaging in personal services and other services is increased, but the proportion of large amplitude engaged in the construction industry decline.

Secondly, the new generation of migrant workers has higher occupation expectation for the future. The old generation of migrant workers migrant workers is mainly carried out from the aspect of economy. They may return to the land at any time. But the new generation of migrant workers not only considers the economic aspects, but the main consideration is the future development. They are engaged in the work which is still mainly physical labor at present, but they have a higher occupation expectation to hope to be able to improve their occupation level in cities and towns. The new generation of migrant workers has a clear direction of the occupation. More and more people want to be managers and technical staff for their own future.

\section{THE WEAKNESSES OF THE NEW GENERATION MIGRANT WORKERS CITIZENIZATION}

\section{A. They lack of labor skills and the employment ability is relatively low}

Migrant workers lack of labor skills and employment ability is relatively low. The new generation of migrant workers doesn't have the necessary professional skills. They do not understand the basic norms of industrial production and is not familiar with city life. They often only engaged in seasonal, assault physical labor and technology simple work. Therefore, learning practical skills in real working period for these migrant workers is too difficult. If they want to learn technology, they can only pay for their own, but the cost is too high for them. They had to give up because they do not have enough money. Their limited technical ability which was simple and repetitive work ability is leaned in work experience. They lack of competitiveness and is easy to be eliminated often because of the adjustment and upgrading of industrial structure.

\section{B. Consumer attitudes' change leads to the high cost of living}

The high cost of living is a major obstacle for migrant workers integrating into the city. This problem is particularly prominent for the new generation of migrant workers. The old generation of migrant workers tended to regard farmers as the reference object, while the new generation of migrant workers is more likely to choose urban residents and migrant workers around as the reference object, resulting in increased cost of living. First of all, from the basic point of consumption, most of the new generation of migrant workers does not have their own housing like the older generation of migrant workers. They need to spend a large part of their income to pay rent Secondly, from the consumer point of view, there is a little other consumption in addition to the daily consumption for the old generation of migrant workers. They often save money. While the new generation of migrant workers has little savings habits, in addition to their daily necessities, other consumption increased significantly, the bulk of consumer and fashion consumption will start to heat up. $\mathrm{TV}$, refrigerator, washing machine, computer and mobile phone has greatly increased. They also spend a lot of money to buy clothes, cosmetics etc.

\section{The new generation of migrant workers has psychological problems}

The majority of migrant workers, especially the new generation of migrant workers have the entrepreneurial dream and dream of getting rich, but the reality is cruel. Migrant workers in the city sometimes feel enormous contrast between their work and treatment and city residents. At the same time, because the citizen right can not be guaranteed because of household registration barriers, they produce a strong sense of being deprived which will also make them produce a lot of discontent mental. In addition, the new generation of migrant workers mostly wants to stay in the city. But when the strong conflict occurs, the new generation of migrant workers is very easy to cause the passenger mentality and the city of apathy and alienation. They begin to self enclosed to refuse to communicate with the outside world.

\section{Migrant workers lack of cultural identity}

Migrant workers' integrating into the city is not only a social economic problem and political participation. In a deeper level, it is a cultural identity. Because of the difference of and cultural and educational level, living habits, work environment and concepts, there is a "cultural 
Table Type Styles" between migrant workers and city residents. So that migrant workers is difficult to really integrate into the city.

\section{THE OPPORTUNITIES OF THE NEW GENERATION MIGRANT WORKERS CITIZENIZATION}

\section{A. The rapid development of new urbanization}

Chinese urbanization has been developing rapidly which can promote the migrant workers urbanization. Since the reform and opening up, the level of urbanization has been greatly improved. As shown in table 1 .

TABLE I. CHINA’S URBANIZATION RATE FROM 1978 TO 2013

\begin{tabular}{|c|c|c|c|}
\hline time & urbanization rate & time & urbanization rate \\
1978 & $17.92 \%$ & 1996 & $30.48 \%$ \\
1979 & $18.96 \%$ & 1997 & $31.91 \%$ \\
1980 & $19.39 \%$ & 1998 & $33.35 \%$ \\
1981 & $20.16 \%$ & 1999 & $34.78 \%$ \\
1982 & $21.13 \%$ & 2000 & $36.22 \%$ \\
1983 & $21.62 \%$ & 2001 & $37.66 \%$ \\
1984 & $23.01 \%$ & 2002 & $39.09 \%$ \\
1985 & $23.71 \%$ & 2003 & $40.53 \%$ \\
1986 & $24.52 \%$ & 2004 & $41.76 \%$ \\
1987 & $25.32 \%$ & 2005 & $42.99 \%$ \\
1988 & $25.81 \%$ & 2006 & $43.90 \%$ \\
1989 & $26.21 \%$ & 2007 & $44.94 \%$ \\
1990 & $26.41 \%$ & 2008 & $45.68 \%$ \\
1991 & $26.94 \%$ & 2009 & $46.59 \%$ \\
1992 & $27.46 \%$ & 2010 & $49.68 \%$ \\
1993 & $27.99 \%$ & 2011 & $51.27 \%$ \\
1994 & $28.51 \%$ & 2012 & $52.57 \%$ \\
1995 & $29.04 \%$ & 2013 & $53.73 \%$ \\
\hline
\end{tabular}

\section{B. The support of national policy}

Along with China's continuous progress of urbanization and industrialization, urbanization of new generation of migrant workers has been the strong support of national policy. At the beginning of 2010, it is pointed out in the central document no. 1, encourage the conditional cities make the migrant workers that have a stable career and live in the city for a certain fixed number of years into the urban housing security system step by step to focus on solving the problem of new generation of migrant workers. Before that, China also have issued a series of policies which aim to promote the new generation of migrant workers urbanization, such as the 2004 " The notice of further improving migrant workers' employment environment, and the 2006 " Several opinions on solving the problem of migrant workers of State Council ".

\section{The contribution of migrant workers in the economic development has gradually been acknowledged by society}

The great contribution of migrant workers in China's economic and social development has been recognized by the media and public. With the new generation of migrant workers as a new and large group of workers appears, the industrialized city would deny that migrant workers will be the backbone of Chinese industrial arena as the future of industrial workers. China's migrant workers were also nominated for "time" person of the year.

\section{THE THREATS OF THE NEW GENERATION MIGRANT WORKERS CITIZENIZATION}

\section{A. Limitation of household registration system}

The reform of China's urban and rural household register system is still not completely. The local governments tend to the citizens in the provision of social welfare and public services, ignoring the migrant rights, which hinder the free flow of new generation of migrant workers in the city. The existing household registration system has seriously restricted the new generation of migrant workers employment opportunities. There are many difficulties for the new generation of migrant workers to settle down in the city, such as too low income, housing, social security, taking care of the elderly, their children's education problems, etc. Although there are a number of provinces which have established the unified household registration management system between urban and rural areas at present in China, which gradually cancelled agricultural registered permanent residence and non-agricultural registered permanent residence. The difference between urban and rural identity is difficult to completely be eliminated in the short term. There are a lot of preconditions for the new generation of migrant workers to settle in the city. So it is difficult to settle in the town truly.

\section{B. The urbanization level is lag and the city capacity is limited}

Because the bearing of the third industry is mainly the town, the lag of the urbanization of China restricted the development of the third industry, making the town can accept limited employment. With the number of the new generation of migrant workers coming into the cities and towns increased greatly, more and more severe employment situation appears, impacting the stable employment of new generation of migrant workers in the city. Also the level of urbanization of China is lag and the regional development is not balanced. Most of the new generation of migrant workers from the Midwest went to the eastern region to work. They are mainly distributed in the high level of urbanization and economic developed area such as Guangdong, Zhejiang and Jiangsu. In these areas, the population increased rapidly, while the government did not take the corresponding planning. It is difficult to accept a large number of the new generation of migrant workers into citizens in a short period of time, which increases the pressure of the city, hinders the new generation of migrant workers to local transfer and increases the cost of urbanization.

\section{CONCLUSIONS}

In the scientific method of SWOT analysis, analysis of the strengths and weaknesses and the opportunities and threats in the external environment of the new generation of migrant workers urbanization synthetically to come to the following conclusions, as shown in figure 1. 


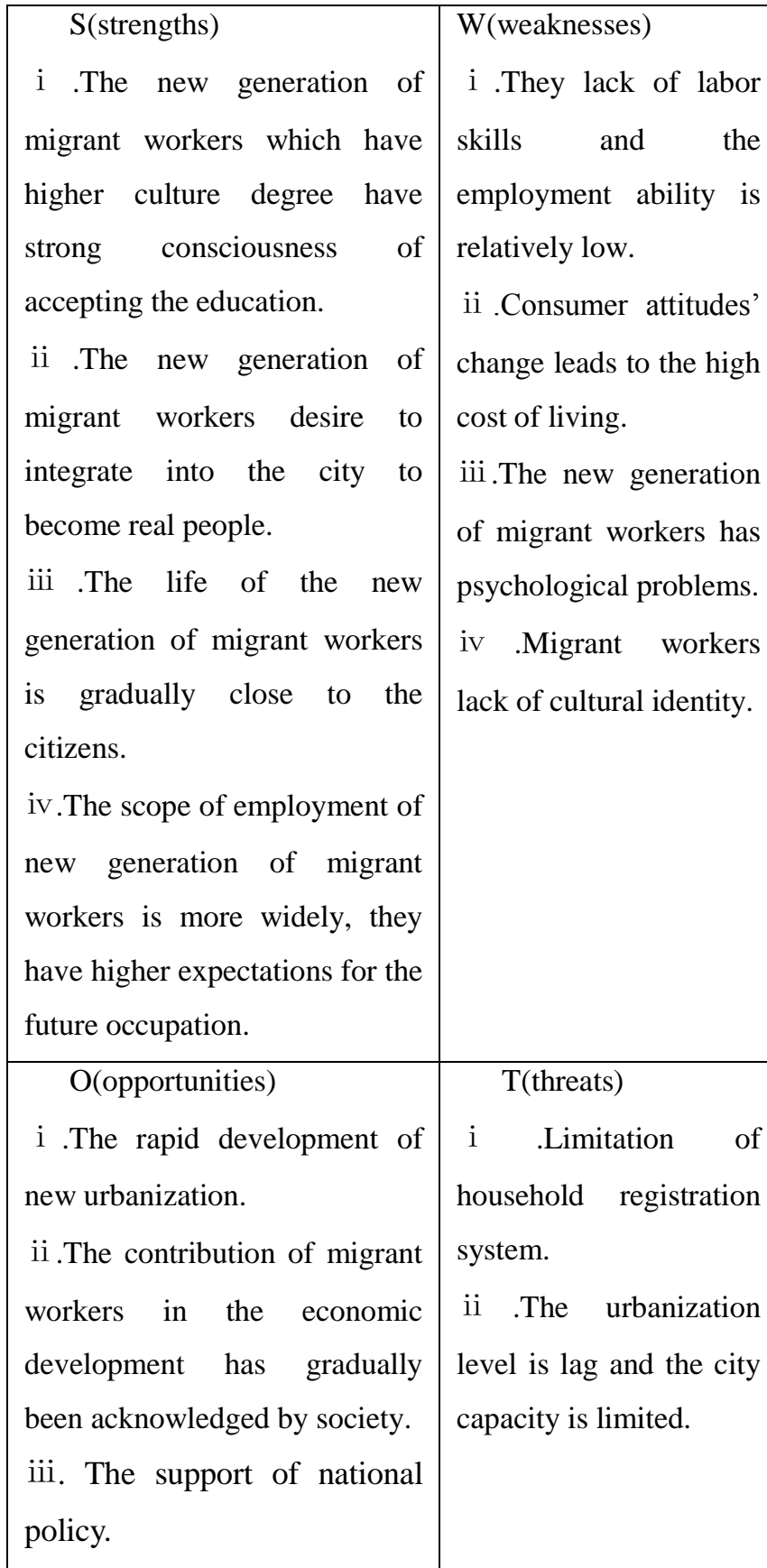

Figure 1. The SWOT analysis of the new generation of migrant workers citizenization

Overall, the SWOT can be divided into two parts: the first part of SW is mainly used to analysis the internal conditions and the second part of OT is mainly used to analysis the external conditions. This method can be used to find favorable and worth promoting factors, and the things against him and avoid them, the existing problems and find out the solutions, and define the development direction in the future. And enumerate the research object, according to the matrix form, and then use the thought of system analysis, the various factors each other match analysis, from which a series of corresponding conclusions. As shown in figure 2 .

\begin{tabular}{|c|c|l|}
\hline enternal environment & Strengths -S & Weaknesses -W \\
\hline Opportunities -O & $\begin{array}{l}\text { Part SO } \\
\text { Make use of } \\
\text { strengths and } \\
\text { take the } \\
\text { opportunities }\end{array}$ & $\begin{array}{l}\text { Part WO } \\
\text { Take the } \\
\text { opportunities } \\
\text { and overcome } \\
\text { the weaknesses }\end{array}$ \\
\hline Threats -T & $\begin{array}{l}\text { Part ST } \\
\text { Make use of } \\
\text { advantages } \\
\text { and avoid the } \\
\text { threats }\end{array}$ & $\begin{array}{l}\text { Peduce the } \\
\text { weaknesses and } \\
\text { avoid the } \\
\text { threats }\end{array}$ \\
\hline
\end{tabular}

Figure 2. SWOT matrix analysis model

Migrant workers urbanization involves a series of problems in the urbanization and the social management system reform etc. Solving the problem of migrant workers urbanization is helpful to improve the quality and efficiency of urbanization, and enhance the power of city economic development. Also it helps to eliminate the drawbacks of the social management system and form a good situation of political, economic, social benign interaction. Therefore, migrant workers should share the fruits of reform and development with urban residents to realize the migrant workers urbanization.

\section{REFERENCES}

[1] Niu Xiaoye, Cao Zhiwen, Cui Yushu. The discussion on integration into the city for the new generation of migrant workers' -- Taking Hebei Province as an example[J]. Economic Research Guide, 2011(27)

[2] He Xionglang, Yang Jirui. To explore the new situation of China's new generation of migrant workers citizenization[J]. Journal of Zhoukou Normal University, 2012(1)

[3] Yang Lina, Zhang Guoping. Analysis of the current generation of migrant workers occupation guidance[J]. Century Bridge, 2012(1)

[4]Li Weidong. Study of adaptation of new generation of migrant workers in the city[J]. Beijing Social Sciences, 2009(4):29-33

[5] Lv Wenfeng. Problems and solutions faced by the second generation of migrant workers citizenization[J]. Economic Research Guide, 2010(23):46-47

[6]Cai Zhigang. Study on the new generation of migrant workers citizenization[J].Theoretical exploration,2010(1)

[7] Zhang Hua, Xia Xiangli. Influencing factors analysis of the new generation migrant workers citizenization intention in Northwest China[J]. Journal of Inner Mongolia Agricultural University, 2011(1)

[8] Zhu Guoping. Analysis on the features and urbanization of the new generation of migrant workers[J]. Journal of Shanxi College for Youth Administrators, 2011(3)

[9] Huang Kun. Analysis on the system of China migrant workers citizenization[M].Beijing: China Renmin University Press,2011: 252.

[10] Liu Xiaonian. Study on the policy of migrant workers citizenization from the perspective of subject[M].Changsha: Hunan People's Publishing House, 2010:21.

[11] Li Min. Study on the issues of the new generation of migrant workers in recent years[J]. Journal of Beijing Agricultural Vocation College, 2010(1) 